\title{
Uyku Teknisyenleri: Gecenin Uykusuzları
}

\author{
Sleep Technicians: Sleepless of the Night
}

\author{
Zerrin PELIN (iD
}

ÖZ

Uyku teknisyenleri, uyku bozukluklarının tanılanması için kullanılan polisomnografi adı verilen test ile evde uyku monitorizasyonlarının yapılması ve solunum hastalarında PAP ad1 verilen tedavi yönteminin uygulanmasında hekim ile birlikte çalışan yardımcı sağlık elemanlarıdır. Hastanın uyku laboratuarına girişinden itibaren hastaya ilişkin soru formlarının uygulanması, elektrodların yerleştirilmesi, uykuda hasta takibi ve gereğinde hastaya müdahale gibi birçok görevi olan uyku teknisyenleri uyku çalışmalarının en önemli parçasını oluşturmaktadır. Bu derlemede uyku teknisyenliği mesleğinin görevleri, sorumlukları ve zorlukları ele alınmıştır.

Anahtar Kelimeler: Uyku teknisyenliği, Polisomnografi, Elektronörofizyoloji

\begin{abstract}
Sleep technologists work under the general supervision of the medical director to provide comprehensive evaluation and treatment of sleep disorders including in center and home sleep apnea testing, diagnostic and therapeutic interventions. They are the most important part of sleep laboratories who are responsible for comprehensive patient care, direct patient education, placement of electrodes and follow up the patients during sleep. In this review, the duties, responsibilities and difficulties of the sleep technologist are discussed.
\end{abstract}

Keywords: Sleep technician, Polysomnography, Electroneurophysiology

Zerrin PELIN (四)

Hasan Kalyoncu Üniversitesi, Sağllk Bilimleri Fakültesi, Gaziantep

Somnus Uyku Bozuklukları Merkezi, Istanbul

e-mail: zerrinp@gmail.com

\section{GÍRIŞ}

Yetmişli yılların başlarından itibaren uykuda ortaya çıkan solunum ve hareket bozuklukları ile uykuda ortaya çıkan anormal davranışların ya da epileptik aktivitelerin ortaya konabilmesi amaciyla, gece uykusu boyunca beyin dalgalarının, göz hareketlerinin, solunum faaliyetlerinin, kandaki oksijen yüzdesinin, kas aktivitesinin, kalp ritminin ve gerekli olduğu durumlarda özafagus asiditesi, intratorasik basınç gibi farklı birçok parametrenin ölçülmesi ile polisomnografi adını verdiğimiz uyku tetkikleri tıbbi tanı yöntemleri arasında yerini almıştır. Polisomnografi sırasında kaydı yapılan her bir parametre için farklı aksesuarların hastaya uygulanması ve bu kayıtların büyük bir titizlikle gece boyunca monitorizasyonu gerekmektedir. $\mathrm{Bu}$ noktada, uyku laboratuvarlarının vazgeçilmez kişileri uyku teknisyenleri devreye girmektedir.

Uyku bozukluklarının teşhis ve solunum bozukluğu olan hastaların tedavisi amacıyla, hekimin isteği doğrultusunda, özel kayıt donanımlarını kullanarak polisomnografi çekimi yapma ve "positive airway pressure (PAP)" cihazlarının titrasyonu eğitimini almış sertifikalı kişi uyku teknisyenidir. Ülkemizde 80'li yılların sonlarına doğru başlayan uyku çekimlerinde, uyku alanında yetişmiş hocalarımızın eğitim vererek hazırladığ 1 teknisyenler görev yapmakta iken, daha sonra uyku dernekleri tarafindan eğitim verilerek, sertifikalı hale gelen uyku teknisyenleri görev yapmakta idi. Son yıllarda ise üniversitelerin Sağlık Hizmetleri Meslek Yüksekokulları bünyesinde kurulan "Elektronörofizyoloji Teknikerliği” programlarından 2 yıl eğitim alarak mezun olan teknikerler uyku laboratuvarlarında görev yapmaktadır. Avrupa ve Amerika'da uyku teknisyenlerinin yeterlilik için girdikleri bir sınav bulunmakta bu sınavlarda başarılı olan uyku teknisyenlerinin polisomnografi kaydı değerlendirme 
ve rapor yazma yetkinlikleri de bulunmaktadır. Ülkemizde henüz bu yeterliliğin verildiği bir sınav bulunmamaktadır.

Uyku teknisyenlerinin, gece ya da gündüz uygulanan tetkikler için gerekli polisomnografi cihazlarını ve ekipmanlarını, PAP cihazlarını, oksimetri, kapnografi ve aktigrafi vb. gibi cihazların teknik özelliklerini çok iyi bilip, uyku çekimi sırasında bir problem ortaya çıktığında cihazlara müdahale edebilecek yeterliliğe sahip olması gereklidir. Polisomnografi testi, hasta sayısının çok olması ve uyku laboratuvarı sayısının yetersiz olması nedeniyle hastaların, uzun randevu süresini beklemeleri gereken bir test olduğundan, yapılan testin sağlıklı ve eksiksiz olması hem hasta hem de uyku laboratuvarları açısından büyük önem taşımaktadır. Dolayısıyla uyku teknisyeninin bilgili, tecrübeli ve iyi yetişmiş olması uyku testinin sağlıklı değerlendirilebilmesi için gerekli temel şarttır. Bir uyku laboratuarında uyku teknisyeni doğru bir şekilde kayitlama yapamazsa, hekimin o verilere dayanarak hastaya doğru tedavi uygulama imkanı bulunmamaktadır. Uyku teknisyenlerinin tüm gece hasta başında kalmaları zorunludur. Gece boyunca kayıtların düzgün ve artefaktsız sürdürülmesini sağlamalı, gece ortaya çıkacak problemleri düzeltebilmeli ve acil durumları fark edip hekime bildirebilmelidirler. Özellikle epilepsi ve parasomni adını verdiğimiz uykuda ortaya çıkan anormal davranışların gözlendiği tablolarda uyku teknisyeninin hastaya anında müdahale edebilir olması, gelişen süreç ile ilgili hekime ayrıntılı bilgi verebilmesi gereklidir.

Uyku teknisyenlerinin hastanın bağlantılarını yapmak ve gece boyu izlemek dişında da görevleri bulunmaktadır: Hastanın uyku laboratuvarına girişinin sağlanıp gece yapilacak uygulama ile ilgili bilgi verme, uyku öncesi ve sonrası anket formlarının düzgün bir şekilde doldurulmasının sağlanması, takılan elektrodların düzgün çalışmasını sağlamak ve gerekli kontrollerin yapılması, gece artefakt oluşması halinde bunu fark etmek ve düzeltilmesini sağlamak, PAP titrasyonu planlandıysa, hastaya yapılacak işlemi anlatmak, uygun maskeyi seçmek, hastayı maskeye alıştırmak ve polisomnografi testi bittiğinde elektrodların uygun şekilde sökmek, malzemelerin temizliğini ve bakımını yapmak, eksik ya da bozuk bir ekipman varsa bunları bildirmek gibi görevler uyku teknisyeninin sorumluluğu altındadır.

Uyku teknisyenliği zor bir meslektir. Geceleri çalışmak ve herkesin aktif olduğu gündüz saatlerinde uyumak kişiyi zorlayan, kimi zaman depresyona sokan bir süreç olabilir. Bu iş, teknik olarak da öğrenilmesi zor bir iş olduğundan emek harcamaya başlamadan iyi düşünülmesi ve karar verilmesi gerekir. Okulda öğretilen bilgilerin yanında pratik olarak bir uyku teknisyeninin yetişmesi kişinin yeteneğine de bağlı olarak 2-5 sene sürmektedir. Dolayısıyla çok sabır ve emek gerektiren bir iştir. Kişinin gece uykusuzluğa dayanıklı olması, sosyal hayatını bu yönde organize etmesi, sabırlı ve hastaya karşı şefkatli bir yapıda olması gerekmektedir. Diğer taraftan hastaların kimseyle paylaşamadıkları uyku problemlerini görmek, onlara yardımcı olmak, tedavilerini yapmak, onların teşekkürlerini almak ve onlara şifa veren sürecin bir parçası olmak, uyku işi ile uğraşan herkesin en büyük keyfidir.

Uyku bozuklukları, hastalıkların tanınması ile birlikte hasta sayısının giderek arttığı bir hastalık grubudur. $\mathrm{Bu}$ hastalıkların teşhisinin konulabilmesi için uyku laboratuarlarının en verimli şekilde çalışabilmesi ve hastalara hizmet verebilmesi gerekmektedir. Uyku laboratuvarları, temizlik görevlisinden doktora, randevuyu organize eden sekreterden uyku teknisyenine kadar bir bütün olarak çalışması gereken bir organizasyondur. Uyku teknisyenleri bu oluşumun olmazsa olmazıdır ve büyük fedakarlıkla bu işleri yapmaktadırlar. Gecelerin olmazsa olmaz kişileridir.

\section{KAYNAKLAR}

1. Berry RB, Brooks R, Gamaldo CE, Harding SM, Lloyd RM, Marcus CL, et al. The AASM Manual for the Scoring of Sleep and Associated Events: Rules, Terminology and Technical Specifications, Version 2.1. www.aasmnet.org, Darien, Illinois: American Academy of Sleep Medicine, 2014.

2. American Academy of Sleep Medicine. International classification of sleep disorders (ICSD), 3rd ed. Darien, IL: American Academy of Sleep Medicine, 2014.

3. Chokroverty S. Polysomnography and related procedures. In: Hallett M, ed. Movement Disorders: Handbook of Clinical Neurophysiology. vol. 1. Amsterdam: Elsevier; 2003:139151.

4. Chokroverty S, Radtke R, Mulligan J. Polysomnography: technical and clinical aspects. In: Schomer DL, Lopes Da Silva FH, eds. Niedermeyer's Electroencephalography: Basic Principles, Clinical Applications, and Related Fields. 6th ed. Philadelphia: Lippincott, Williams and Wilkins; 2011:817-864

5. Siddiqui F, Osuna E, Walters AS, Chokroverty S. Sweat artifact and respiratory artifact occurring simultaneously in polysomnogram. Sleep Med. 2006;7(2):197-199. 